\title{
Influence of the mixing water rate on the plaster thermo- physical properties: Experimental and dynamic study
}

\author{
Mohamed Touil ${ }^{1, *}$, Amine Lachheb ${ }^{1}$, Rachid Saadani ${ }^{1}$, Mustapha Sanbi ${ }^{2}$, and Miloud Rahmoune $^{1}$ \\ ${ }^{1}$ Laboratory for the Study of Advanced Materials and Applications, FSM-ESTM, Moulay Ismail University, Meknes, Morocco \\ ${ }^{2}$ Team Science and Advanced Technologies, National School of Applied Sciences, Abdelmalek Essaadi University, Tetouan, \\ Morocco
}

\begin{abstract}
The construction industry has long been one of the most energy intensive sectors in the world. Therefore, the development of building materials appears to be one of the effective solutions to this challenge. Plaster is considered among the materials widely used in construction because of its advantageous properties. The present article includes in its entirety two sequential studies. The first one, deals with an experimental analysis of the plaster thermo-physical properties formed by two different mixing water rates, in order to evaluate its effect. While, the second, presents a dynamic simulation results of an individual building subjected to different climatic conditions of Morocco and in which no energy efficiency measures were carried out, through simulations series realized by using TRNSYS software. The latter study was intended to quantify the developed materials impact, on the energy required to maintain the occupants comfort. The findings obtained in this work, revealed the positive influence of increasing the mixing water rate. Thus, reducing the plaster thermo-physical properties, delaying the heat transmission, and significantly decreasing the building energy consumption devoted to heating and cooling.
\end{abstract}

\section{Introduction}

The construction sector is one of the areas that directly interfere with the environment. It consumes an important part of energy and material resources through the industrial production chains of civil construction [1]. In this context, the research and development of new materials with low energy consumption has become one of the main objectives of the sustainable construction strategy.

Gypsum is considered among the conventional building materials widely used in the construction industry for thousands of years in many interior applications [2], thanks to its advantageous properties compared to other materials, such as its low energy consumption, its interesting thermo-physical properties, its fire resistance, its ecological industrial production, and also its attractive aesthetic aspect [3-4]. In fact, gypsum $\left(\mathrm{CaSo}_{4} \cdot 1 / 2 \mathrm{H}_{2} \mathrm{O}\right)$ is a porous material produced from gypsum through a dehydration process under temperature conditions between 100 and $180^{\circ} \mathrm{C}$ [5]. Its solubility in water allows the production of solid and hard parts depending on the operation purpose.
From a thermal point of view, despite its effective properties in thermal insulation and moisture regulation. Plaster remains a material affecting the buildings energy efficiency. This implies the need to improve the methods and conditions of its elaboration. Among important influencing parameters, which affect its thermal behavior, is the preparation temperature, the powder purity, the duration and speed of the paste blending and the mixing water rate used. The latter, is treated by several researchers [6-7], who have evaluated the plasters thermomechanical properties, formed by different reports.

The objective of the present study is to examine experimentally the effect of two different mixing water ratios on the thermo-physical properties of Moroccan plaster, produced in particular from gypsum of Safi city. The (W/P) ratio studied are 0.5 and 0.7 . Also, a numerical simulation was carried out to evaluate their impact on the energy performances and thermal comfort of an individual building subjected to the different Moroccan climatic conditions, using the TRNSYS software. These materials impact would be established through the identification of heating and cooling loads necessary to maintain the ideal thermal comfort in buildings, as well as comparing the obtained results with technical

*Corresponding author: mohamed.touil.as@gmail.com 
specifications of the performance approach, proposed by the thermal regulation of construction in Morocco [1].

\section{Experimental investigation}

\subsection{Preparation of the samples}

The samples formulated in this study were prepared by two different $\mathrm{W} / \mathrm{P}$ rates $(0.5$ and 0.7$)$ of the plaster mass according to the European standard 13279-1 [8]. The manufacturing process is based on several steps. Firstly, the water amount needed for blending is added into a container, followed by slow distribution of the plaster powder on the water surface. Then, a gentle manual kneading of the paw is carried out until a homogeneous mixture is obtained. Afterwards, the latter is poured into molds with dimensions $27 * 27 * 4 \mathrm{~cm}^{3}$, and undergoes a forced drying in a temperature of $50 \pm 1{ }^{\circ} \mathrm{C}$ until losing all the water content present in its structure. Thus, the manufactured pieces are kept in ambient conditions for 28 days before the thermo-physical characterization (Fig 1). The table 1 shows the prepared samples characteristics.

Table 1. Samples formulation.

\begin{tabular}{ccc}
\hline W/P ratio & Number of samples & Designation \\
\hline 0.5 & 2 & $\mathrm{P}: 0.5$ \\
\hline 0.7 & 2 & $\mathrm{P}: 0.7$ \\
\hline
\end{tabular}

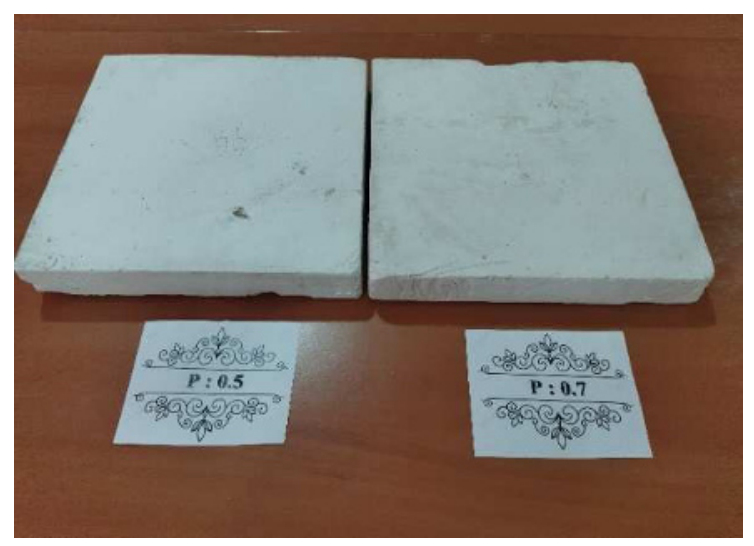

Fig. 1. Samples studied with their formulation

\subsection{Experimental device}

The experimental instrument used for specimens thermophysical characterization is the so-called box method (Fig 2). This method allows to determine two main thermal properties according to European standard [9], namely the thermal conductivity and the thermal diffusivity.

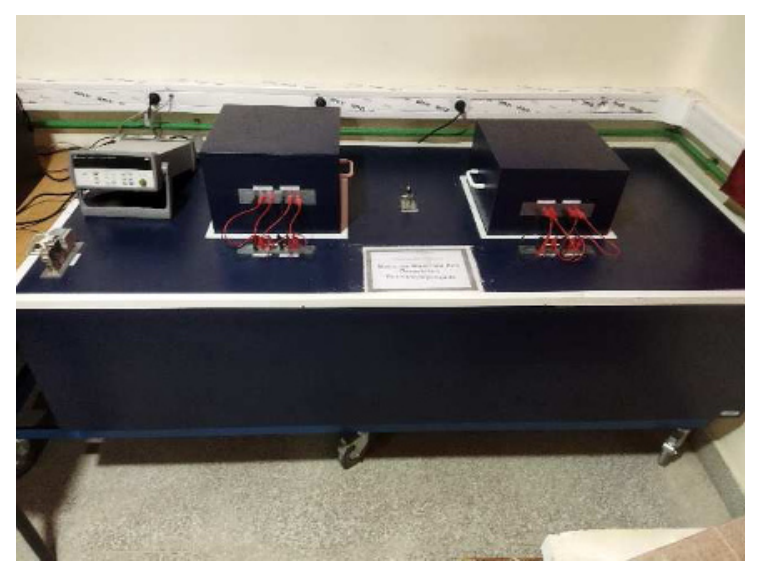

Fig. 2. EI700 measuring cell

The principle of thermal conductivity measurement is based on the application of a unidirectional heat flow on sample upper surface to be tested by a heating film controlled by a voltage regulating console. While the temperature gradient is created through the cooling of the lower face by an exchanger powered by a cryostat. Finally, the measurements are taken in steady state through the system energy balance described by equations 1 and 2 , and the thermal conductivity calculation is made from the equation 3 .

$$
\begin{aligned}
& { }_{\mathrm{H}}={ }_{\mathrm{L}}+\mathrm{C} \\
& \frac{V^{2}}{R}=K\left(\begin{array}{ll}
T_{b} & T_{a}
\end{array}\right)+\frac{-}{e} S\left(T_{s} \quad T_{i}\right) \\
& \exp =\frac{e}{S\left(T_{s} T_{i}\right)}\left[\frac{V^{2}}{R} \quad K\left(\begin{array}{ll}
T_{b} & T_{a}
\end{array}\right)\right]
\end{aligned}
$$

Where:

$\Phi_{\mathrm{H}}$ : Total imposed heat flux in $\mathrm{W}$;

$\Phi_{\mathrm{L}}$ : Heat flux lost through the box in $\mathrm{W}$;

$\Phi_{\mathrm{C}}$ Conduction heat flux through the sample in $\mathrm{W}$;

$\mathrm{V}$ : Electrical voltage in V;

$\mathrm{R}$ : Electrical resistance in $\mathrm{Ohm}$;

$\mathrm{K}$ : Heat loss constant through the boxe inW/K;

$\lambda_{\text {exp: }}$ Thermal conductivity in $\mathrm{W} / \mathrm{m} . \mathrm{K}$;

$\mathrm{T}_{\mathrm{b}}$ : Temperature of the box in ${ }^{\circ} \mathrm{C}$;

$\mathrm{T}_{\mathrm{a}}$ : Ambiant temperature in ${ }^{\circ} \mathrm{C}$;

$\mathrm{T}$ s: Temperature of hot side in ${ }^{\circ} \mathrm{C}$;

$\mathrm{T}_{\mathrm{i}}$ : Temperature of cold side in ${ }^{\circ} \mathrm{C}$;

e: Thikness in m;

S: Surface of the sample in $\mathrm{m}^{2}$.

On the other hand, the thermal diffusivity is measured in the second box through a power application of $1000 \mathrm{~W}$, on the bottom face of the sample for an adjustable time of a few seconds. Then to identify the times corresponding to the points for which $1 / 2,2 / 3$ and $5 / 6$ of the maximum temperature of the non-irradiated face. Thus, the experimental model of Degiovanni [10] allows to calculate approximately the thermal diffusivity value (equations 4). 


$$
\left\{\begin{array}{l}
{ }_{1}=\frac{e^{2}}{t_{5 / 6}^{2}}\left(\begin{array}{ll}
1.15 t_{5 / 6} & 1.25 t_{2 / 3}
\end{array}\right) \\
2=\frac{e^{2}}{t_{5 / 6}^{2}}\left(\begin{array}{ll}
0.76 t_{5 / 6} & 0.926 t_{1 / 2}
\end{array}\right) \\
3=\frac{e^{2}}{t_{5 / 6}^{2}}\left(\begin{array}{ll}
0.618 t_{5 / 6} & 0.862 t_{1 / 3}
\end{array}\right) \\
\text { exp }=\frac{\left({ }_{1}+{ }_{2}+{ }_{3}\right.}{3}
\end{array}\right\}
$$

$\alpha_{\text {exp }}$ Thermal diffusivity $\mathrm{m}^{2} / \mathrm{s}$.

For other thermo-physical parameters such as heat capacity; it is calculated from the experimental results of thermal conductivity, diffusivity and density by the equation 5 .

$$
C_{P}=\frac{\exp }{\exp \exp }
$$

$\mathrm{C}_{\mathrm{p}}$ : Thermal capacity in $\mathrm{J} / \mathrm{kg} . \mathrm{K}$; $\rho_{\text {exp: }}$ : Density in $\mathrm{kg} / \mathrm{m}^{3}$.

\section{Results and discussion}

\subsection{Thermo physical Properties}

In this section, all properties obtained by the thermophysical characterization of the formulated materials are represented. Indeed, the (Table 2) shows a summary of the thermo-physical parameters obtained, which are thermal conductivity, thermal diffusivity, heat capacity and bulk density.

Table 2. Results of the thermo physical properties.

\begin{tabular}{ccccc}
\hline Sample & $\begin{array}{c}\text { Thermal } \\
\text { conductivity } \\
\text { W/m.K }\end{array}$ & $\begin{array}{c}\text { Heat } \\
\text { capacity } \\
\text { J/kg.K }\end{array}$ & $\begin{array}{c}\text { Density } \\
\mathrm{kg} / \mathrm{m}^{3}\end{array}$ & $\begin{array}{c}\text { Thermal } \\
\text { diffusivity } \\
\mathrm{m}^{2} / \mathrm{s}\end{array}$ \\
\hline $\mathrm{P}: 0.5$ & 0.440 & 431.58 & 1409.8 & $7.24^{*} 10^{-7}$ \\
\cline { 2 - 5 } & 0.443 & 435.96 & 1409.4 & $7.22^{*} 10^{-7}$ \\
\hline $\begin{array}{c}\text { Mean } \\
\text { value }\end{array}$ & 0.442 & 433.77 & 1409.6 & $7.23 * 10^{-7}$ \\
\hline $\begin{array}{c}\text { Standard } \\
\text { deviation }\end{array}$ & $2.25^{*} 10^{-3}$ & 3.093 & 0.24 & $1.3 * 10^{-9}$ \\
\hline P : 0.7 & 0.371 & 713.93 & 1230.5 & $4.2^{*} 10^{-7}$ \\
\cline { 2 - 5 } & 0.374 & 706.20 & 1230.7 & $4.3 * 10^{-7}$ \\
\hline $\begin{array}{c}\text { Mean } \\
\text { value }\end{array}$ & 0.373 & 710.06 & 1230.6 & $4.2^{*} 10^{-7}$ \\
\hline $\begin{array}{c}\text { Standard } \\
\text { deviation }\end{array}$ & $2.06 * 10^{-3}$ & 5.464 & 0.1697 & $5.5^{*} 10^{-9}$ \\
\hline
\end{tabular}

(3 and 4). It is clear that increasing the W/P ratio during the preparation of the plaster paste, reduces significantly the thermal conductivity from 0.442 to $0.373 \mathrm{~W} / \mathrm{m} . \mathrm{K}$, whish correspond to a reduction rate of $15.56 \%$. While the thermal diffusivity decreases from $7.23 .10^{-7}$ to $4.27 .10^{-7} \mathrm{~m}^{2} / \mathrm{s}$ with a significant lowering rate of $40.91 \%$. On the other hand, the thermal capacity has experienced an opposite evolution, it has increased from 433.77 to $710.06 \mathrm{~J} / \mathrm{kg} . \mathrm{K}$. As for the plaster density, the sample P: 0.5 appears slightly denser than P: 0.7 . These results obtained can be explained by pores creation inside materials structure, allowing subsequently to increase their porosity. Therefore offering to the plaster a more insulating character and less restituting of the heat. A similar behavior was found by several researchers who evaluated the effect of W/P ratio on the plaster thermophysical properties such as Alrawashdeh et al. [11], Madu et al[12] et Ben Mansour et al. [6]. Or even by using other compounding solutions such as water and tragacanth resin employed in the work of Bicer et al. [13].

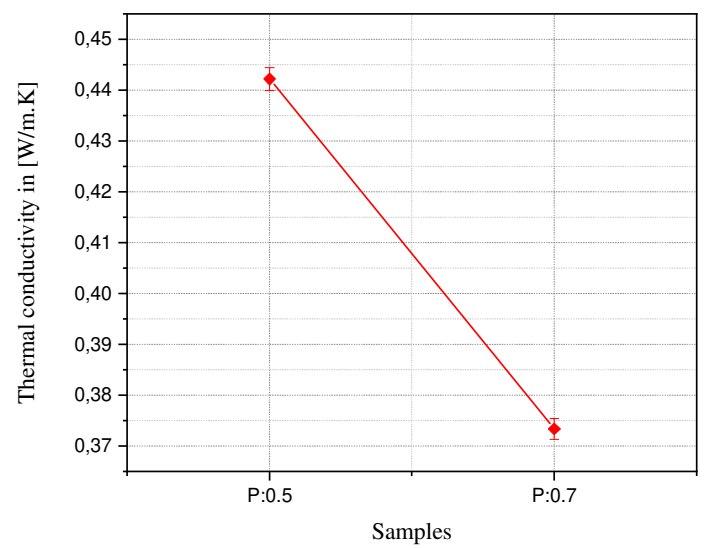

Fig. 3. Thermal conductivity evolution as a function of the sample type.

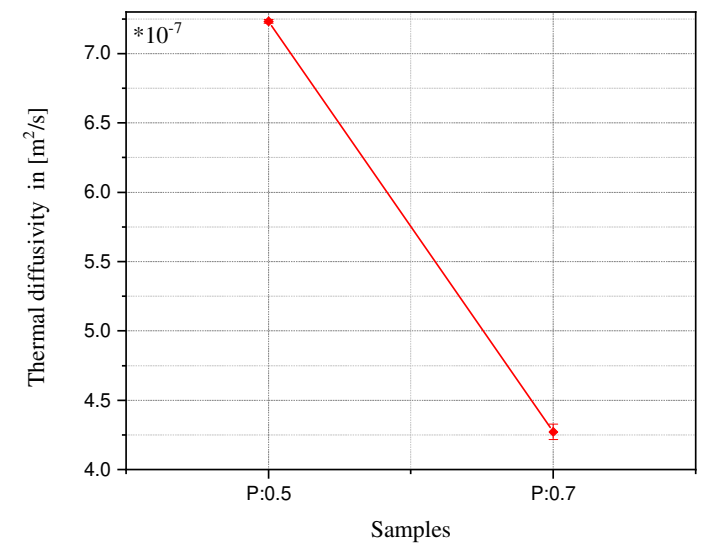

Fig. 4. Thermal diffusivity evolution as a function of the sample type.

\subsection{Dynamic simulation of the building}

The dynamic thermal simulation through the TRNSYS software allows to study virtually the predictive behavior 
of buildings in conditions close to reality. indeed, the transient modeling process is carried out through the exploitation of the component (type 56) which calls upon TRNBuild used to capture the information necessary for the simulation of the studied building such as the architectural composition of the envelope and the scenarios affecting the occupants thermal comfort (heating / air conditioning, ventilation, air infiltration, gains, and the rate of occupancy of the house...).

\subsubsection{Building description}

The base building studied has a total area of $75\left[\mathrm{~m}^{2}\right]$ at ground level, oriented towards the south and has 5 zones (bedroom, living room, kitchen, entrance, and a bathroom/toilet). In fact, table 3 represents a description of its elementary composition, as well as figures 5 and 6 represent its architectural plan and its 3D geometrical model respectively.

Table 3. Basic composition of the building construction.

\begin{tabular}{cc}
\hline Building element & Composition \\
\hline \multirow{3}{*}{ External walls } & Cement mortar $(2 \mathrm{~cm})$ \\
& Hollow brick $(7 \mathrm{~cm})$ \\
& Air blade $(10 \mathrm{~cm})$ \\
& Hollow brick $(7 \mathrm{~cm})$ \\
& Cement mortar $(2 \mathrm{~cm})$ \\
\hline \multirow{2}{*}{ Internal walls } & Cement mortar $(2 \mathrm{~cm})$ \\
& Hollow brick $(7 \mathrm{~cm})$ \\
& Cement mortar $(2 \mathrm{~cm})$ \\
\hline High floor & Plaster $(3 \mathrm{~cm})$ \\
& Cement mortar $(5 \mathrm{~cm})$ \\
& Slab $(16 \mathrm{~cm})$ \\
Low floor & Screed $(1 \mathrm{~cm})$ \\
& Slab $(10 \mathrm{~cm})$ \\
& Cement mortar $(5 \mathrm{~cm})$ \\
Glazing & Tile $(1 \mathrm{~cm})$ \\
\hline & Simple window $\left(\mathrm{U}^{2}\right.$. Kalue $;$ g_value $\left.=0.88\right)$ \\
\end{tabular}

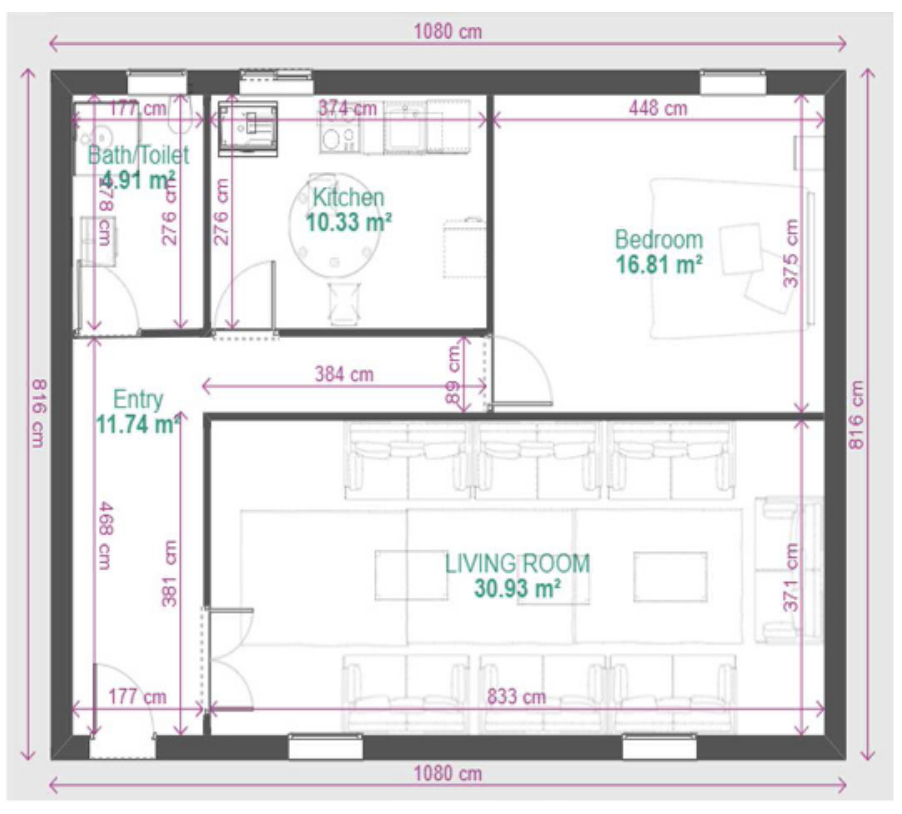

Fig. 5. Architectural plan of the building.

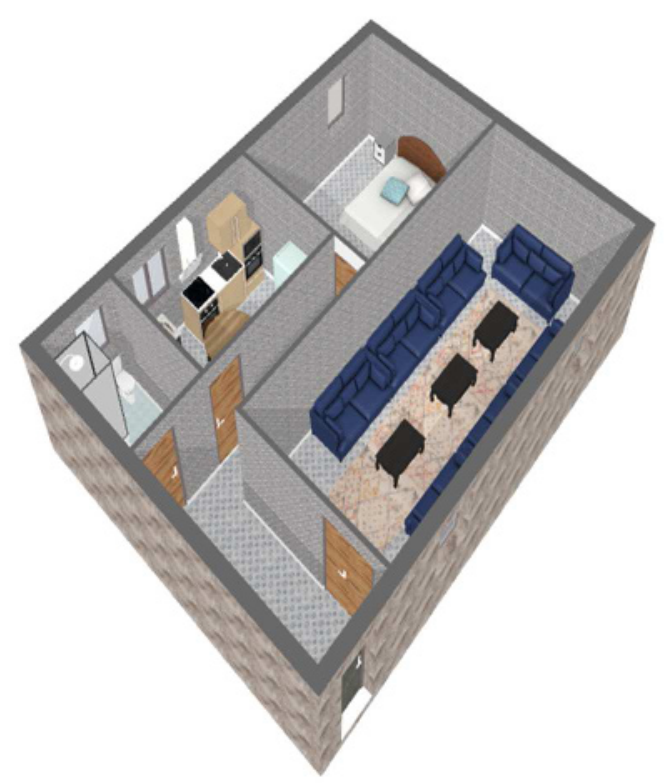

Fig. 6. 3D geometric model of the building.

\subsubsection{Conditions of the dynamic simulation}

The objective of this study is to evaluate the heating and cooling loads necessary to maintain the occupants ideal comfort in a traditional Moroccan building model, through the analysis of two structural combinations of the high floor which include in its composition the studied materials P: 0.5 and P: 0.7. Then, the two combinations are compared to the reference specifications in terms of energy performances in different climatic conditions of Morocco.

Table 4 represents the combinations treated with the variant at the high floor level. While Table 5 shows the 
geographical coordinates of the studied climatic zones classified according to the climatic zonation of the Moroccan thermal regulation approach [1].

Table 4. Processed combinations for dynamic simulation and their formulations.

\begin{tabular}{cc}
\hline Formulation & high floor \\
\hline Configuration 1 & $\mathrm{P}: 0.5$ \\
\hline Configuration 2 & $\mathrm{P}: 0.7$ \\
\hline
\end{tabular}

Table 5. Geographical coordinates of the studied climatic zones.

\begin{tabular}{ccccc}
\hline Ville & Latitude & Longitude & $\begin{array}{c}\text { Altitude } \\
{[\mathrm{m}]}\end{array}$ & $\begin{array}{c}\text { Climate } \\
\text { zone }\end{array}$ \\
\hline Agadir & $30.4^{\circ} \mathrm{N}$ & $-9.5^{\circ} \mathrm{E}$ & 226 & $\mathrm{Z} 1$ \\
\hline Tangier & $35.7^{\circ} \mathrm{N}$ & $-5.8^{\circ} \mathrm{E}$ & 85 & $\mathrm{Z} 2$ \\
\hline Meknes & $33.8^{\circ} \mathrm{N}$ & $-5.5^{\circ} \mathrm{E}$ & 546 & $\mathrm{Z} 3$ \\
\hline Ifrane & $33.5^{\circ} \mathrm{N}$ & $-5.1^{\circ} \mathrm{E}$ & 1644 & $\mathrm{Z} 4$ \\
\hline Marrakech & $33,5^{\circ} \mathrm{N}$ & $-7.6^{\circ} \mathrm{E}$ & 466 & $\mathrm{Z} 5$ \\
\hline Errachidia & $31.9^{\circ} \mathrm{N}$ & $-4.4 \mathrm{E}$ & 1045 & $\mathrm{Z} 6$ \\
\hline
\end{tabular}

The basic assumptions adopted for the dynamic simulation are as follows:

- The initial temperature and humidity are taken at $20^{\circ} \mathrm{C}$ and $50 \%$ respectively;

- The building is unoccupied;

- The thermal bridges and shading effects are not taken into account;

- The heating and air-conditioning system used maintains the comfort of the occupants at set temperatures of $20^{\circ} \mathrm{C}$ and $26^{\circ} \mathrm{C}$, respectively according to the Moroccan standard NM ISO $7730[1]$.

\subsubsection{Simulation results}

Figure 7 represents the internal temperature variation of the bedroom subjected to various climatic conditions of Meknes city, during the year for different combinations studied. From the analysis of it, it is clear that the combination 2 allows to maintain considerably a more reliable indoor temperature. Indeed, for a winter period, the room temperature varies between a minimum of $9.55^{\circ} \mathrm{C}$ in the case of configuration 2 and $9.46^{\circ} \mathrm{C}$ in the case of configuration 1 ; that is a significant difference of $0.09^{\circ} \mathrm{C}$. While for a summer period, the internal temperature reaches a maximum of $38.37^{\circ} \mathrm{C}$ in the case of combination 2 and $38.48^{\circ} \mathrm{C}$ in the case of combination 1 , that is to say an amplitude of $0.11^{\circ} \mathrm{C}$. This shows the reliability of increasing the mixing water rate on the thermal comfort parameters, which allows to delay the thermal exchanges through the plaster layer in the high floor composition.

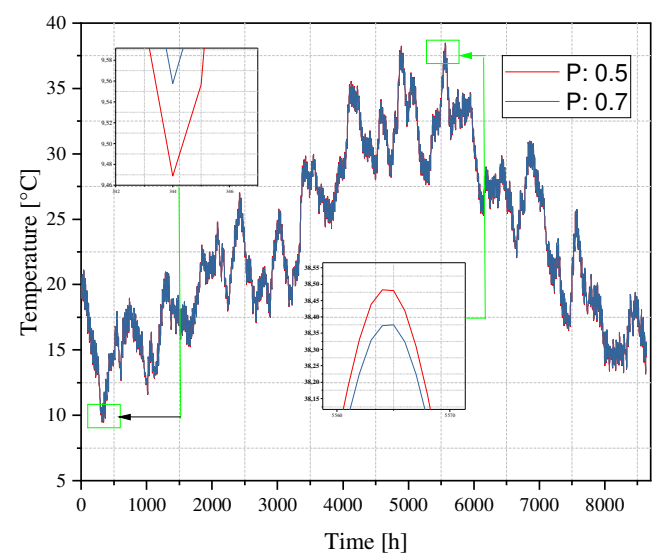

Fig. 7. Bedroom internal temperature subjected to climatic conditions of Meknes city.

Graph 8 illustrates the heating and cooling loads of the building using the two configurations studied in various climatic zones of Morocco. However, the housing heating and cooling needs, vary from one climatic zone to another. In all cities, the configuration 2 with the 0.7 water mixing rate, shows a remarkable efficiency compared to the other one. Consequently, it's maintain a significant decrease for heating and cooling needs. Also, the maximum o the energy appears in Errachidia city (zone 6), while the minimum is noticed in Agadir city (zone 1). The demand for cooling is maximum in zone 6 , while the heating demand is maximum in zone 4 . This can be explained particularly by the climatic conditions that differ from one region to another. Indeed, in all the treated zones, the annual heating and cooling needs exceed the specifications set by the thermal regulation of the construction in Morocco. But, the advantage observed is the efficiency extent of the configuration 2 to reduce the total energy consumption compared to $\mathrm{P}: 0.5$ configuration; that is to say a reduction of $6.52 \%$ for Agadir, $2.61 \%$ for Tangier, $2.40 \%$ for Errachidia, 2.57 $\%$ for Ifrane, $2.37 \%$ for Marrakech and $2.63 \%$ for Meknes. This shows the positive impact and the reliability of increasing the $\mathrm{W} / \mathrm{P}$ ratio during the plaster paste preparation, on the thermal comfort parameters thanks to its thermo-physical properties that allows to delay the thermal exchanges between the interior and exterior. 


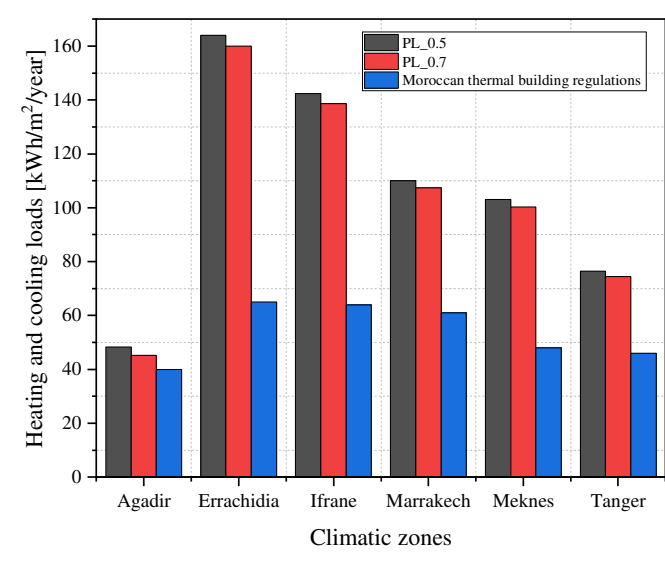

Fig. 8. Heating and cooling needs of the building.

\section{Conclusion}

In this work, the experimental results of the materials thermo-physical characterization prepared with two different mixing water ratios $(0.5$ and 0.7$)$ were presented. The thermal analysis demonstrated the effect of the W/P ratio on gypsum-based building materials. The results obtained showed that the increase of this rate during the formulation of the gypsum paste, allows to produce materials with high thermal performances. Finally, the dynamic simulation of a real building in which no additional energy efficiency measures were taken, revealed that the exploitation of the material with the mixing ratio of 0.7 , allows to reduce significantly the heating and cooling loads necessary to maintain the ideal comfort of the occupants and this appears as a powerful solution to improve the extent of the additional energy efficiency of Moroccan buildings. As a perspective, a mechanical impact study on the mechanical properties of these materials is necessary for large mass fractions of water before their implementation to quantify their ability to withstand the usual buildings mechanical stresses.

\section{References}

1. National Agency for the Development of Renewable Energy and Energy Efficiency in Morocco (ADEREE), Thermal regulation of the construction in Morocco

[2] C. Cardell-Fernández, C. Navarrete-Aguilera, Stud. Conserv. , Pigment and Plasterwork Analyses of Nasrid Polychromed Lacework Stucco in the Alhambra (Granada, Spain), 51, 161-176, (2006).

[3] M. Arikan, K. Sobolev, Cem. Concr. Res., The optimization of a gypsum-based composite material, 32, 1725-1728 (2002)

[4] S. Şahin, S. Karaman, J.T.A.F, The Properties of Expanded Polystyrene - Pumice - Gypsum Blocks as a Building Material, 9, 1 (2012)
[5] The plaster and the cement, the materials of construction, (Reference. Internet 42224/ 3 rd. edition), www. Techniques-ingenieur.fr

[6] M. B. Mansour, C. A. Soukaina, B. Benhamou, S. B. Jabrallah, Ene. Pro., Thermal Characterization of a Tunisian Gypsum Plaster as Construction Material, 42, 680-688 (2013)

[7] F. Hernández-Olivares, M. R. Bollati, M. del Rio, et B. Parga-Landa, Constr. Build. Mater., Development of cork-gypsum composites for building applications ,13, 179-186, (1999)

[8] European Standard EN 13279-1, Gypsum binders and gypsum plasters: definitions and requirements, (2008)

[9] European Standard EN ISO 8990, Thermal insulation: Determination of steady-state thermal transmission properties-calibrated and guarded hot box, (1996)

[10] D. Maillet, S. Andre, A. Degiovanni, J. Phys. III, EDP Sciences, The errors on the thermal diffusivity measured by flash method: confrontation theory-experience, 3, 883-809 (1993)

[11] A. I. Alrawashdeh, A. E. Al-Rawajfeh, A. A. AlBedoor, E. M. Al-Shamaileh, M. N. Al-Hanaktah, J. Chem. Tech. and Metal., production of plaster from gypsum deposits in south jordan: improvement of the setting time, 49, 293-302, (2014)

[12] M. J. Madu, M. B. Ndaliman, B. Oche, Inte. J. Emer. Eng. Res and Tech., Evaluation of Water to Plaster Ratio on Products of Nafada Plaster of Paris (POP), 4, 23-27 (2016)

[13] A. Bicer, F. Kar, Therm. Sci. Eng. Prog., Thermal and mechanical properties of gypsum plaster mixed with expanded polystyrene and tragacanth, 1, 59-65 (2017) 